\title{
Occurrence of Sri Lankan Cassava Mosaic Virus (SLCMV) and its Characterization in West Bengal, India
}

\author{
Nayan Kishor Adhikary ${ }^{*}$, Manoj Kumar and Jayanta Tarafdar \\ Department of Plant Pathology, Bidhan Chandra Krishi Viswavidyalaya, Mohanpur, \\ Nadia-741252, West Bengal, India \\ *Corresponding author
}

\begin{tabular}{|l|}
\hline Ke y w o r d s \\
Begomovirus, \\
Cassava Mosaic \\
$\begin{array}{l}\text { Disease, PCR, } \\
\text { SLCMV, Whitefly }\end{array}$ \\
\hline Article Info \\
\hline $\begin{array}{l}\text { Accepted: } \\
\text { 20 December } 2017 \\
\text { Available Online: } \\
\text { 10 January } 2018\end{array}$ \\
\hline
\end{tabular}

A B S T R A C T
Cassava mosaic disease (CMD) is caused by a number of distinct begomoviruses under the family Geminiviridae. In Indian subcontinent, Indian cassava mosaic virus (ICMV) and Sri Lankan cassava mosaic virus (SLCMV) were reported to be associated with CMD. Although CMD is naturally transmitted by the whitefly (Bemisia tabaci Genn.). While infected stem cuttings is another mean. Natural occurrence of CMD in farmers' field and in the experimental field of the AICRP on Tuber Crops, BCKV was recorded and the virus was detected by PCR-based method. 61-92\% incidence was recorded in farmers' fields of North 24 -Parganas and Nadia districts of West Bengal and variable symptom with mild chlorotic pattern to severe mosaic and distortion of leaf was observed. The incidence and severity of CMD among eight cassava varieties viz. H-5/78, Sree Jaya, Sree vijaya, Sree Prakash, H-118, H-165, CL-590, H-119 was screened and differential response to noticed among the varieties. The intensity of CMD varied significantly with plant age and severity was recorded to be highest at maturity stage. The whitefly mediated artificial inoculation showed the highest $(40.0 \%)$ infection in H-118, while, the lowest $(6.66 \%)$ infection was noted in Sree Vijaya and H-119. The PCR-based detection confirmed the presence of begomovirus in the symptomatic cassava plant samples. Furthermore, the sequence analysis of 511 bp long PCR fragment (FN691429) showed >90\% homology with the SLCMV isolates of India but exhibited somewhat distant relation to SLCMV isolates of Colombo and ICMV. Further characterization of this reported isolate of SLCMV in this state is in progress.

\section{Introduction}

Cassava (Manihot esculenta Crantz.), variously called tapioca, manioc, mandioca and yucca, is a major starchy root crop of the tropics. Cassava, belonging to the family Euphorbiaceae, is a perennial crop native to Brazil of South America (Allen, 1994; Olsen and Schaal, 2001). Cassava is one of the most important staple food crops in the tropics, particularly in Africa. The major constraint for cassava production in Africa and the Indian subcontinent is the Cassava mosaic disease (CMD) caused by viruses included in the genus Begomovirus, caused by a number of distinct begomoviruses (family Geminiviridae). To date, seven begomovirus species have been identified in association 
with CMD, namely African cassava mosaic virus, East African cassava mosaic virus, East African cassava mosaic Cameroon virus, East African cassava mosaic Kenya virus, East African cassava mosaic Malawi virus, East African cassava mosaic Zanzibar virus and South African cassava mosaic virus. The biodiversity of geminiviruses associated with the CMD in India was investigated using PCR to specifically amplify the DNA of Indian cassava mosaic virus (ICMV) or Sri Lankan cassava mosaic virus (SLCMV) and also by using PCR to amplify specific viral genes. Our present investigation was made to detect the mosaic virus infecting cassava plants in West Bengal and its partial characterization.

\section{Materials and Methods}

The field trials were carried out at Horticultural Research Station (HRS), Mondouri, BCKV, Mohanpur, Nadia, West Bengal. Eight varieties of cassava vide: $\mathrm{H}$ 5/78, Sree Jaya, Sree Vijaya, Sree Prakash, H118, H-165, CL-590 and H-119. Stem cuttings of respective germplasms were obtained from AICRP on Tuber Crops, BCKV, Kalyani. The plants were artificially inoculated with whitefly vector under controlled conditions and indexed by PCR based method.

Total DNA was extracted from $100 \mathrm{mg}$ of infected and healthy leaf samples using modified method described by Dellaporta $e t$ al., (1983). The PCR amplified product eluted from the agarose gel and purified by DNA purification kit (K0\#513). The purified product was sequenced by BioServe India Pvt. Ltd. Sequence was compared by BLAST analysis in NCBI. Finally sequence was submitted in EMBL and got accession no. as FN691429. Nucleotide and derived amino acid sequences were compared to the corresponding sequence of Cassava Mosaic Virus available in the genbank database (Table 1). The pair-wise alignments and percent identity matrix of nucleotide and amino acid sequences were performed using Clustal W2 programme from EMBL Sequence Database online. Phylogenetic tree was constructed through Clustal W2 programme, average distance shows using BLOSUM 62.

\section{Results and Discussion}

The incidence of cassava mosaic disease (CMD) was surveyed in two farmers' fields at North 24-Parganas and Nadia districts where the cassava is commercially growing by the NGOs Ashalaya (Don Bosco) at Saguna and Familia in North 24- Parganas. The incidence and severity of CMD was studied in three stages of the crop growth during 4, 5 and 6 months after planting. The incidence of CMD was also recorded in the experimental field of AICRP Tuber Crops at HRS, Mondouri, BCKV during 2008-2009 season 25 randomly selected plants from three blocks of the commercial field of cassava was scored for the incidence of CMD and severity on the basis of 1-5 scale (Hahn et al., 1980).

During the survey in three sites, upto $92 \%$ incidence of the mosaic disease was noticed of farmers' field at Familia, North 24-Parganas and upto $77.33 \%$ incidence was recorded of farmers' field at Saguna, Nadia. The mean incidence of CMD at Familia during 4, 5, and 6 months of crop age ware $82.66 \%, 81.33 \%$ and $92 \%$ respectively. But the severity of CMD ware 1.97, 2.22 and 3.14 respectively. The similar trend in the incidence of CMD was noticed at Ashalaya, Saguna, Nadia. $61.33 \%$ mosaic symptom was noticed at 4 month age of the crop and later $73.33 \%$ and $77.33 \%$ incidence ware recorded during 5 and 6 month age of the crops and the mean severity of CMD ware 1.69, 2.42 and 2.74 respectively. In the experimental field of AICRP on Tuber Crops, Mondouri, BCKV the incidence ranged from $0-4 \%$ only and severity ware $0,0.12$ and 0.24 respectively (Table 2 ). 
The results indicated that in the two farmers' fields that there a gradual increase in symptoms development with the age of the crops, but the severity index was moderately low. In all the infected plants at two areas (Familia and Ashalaya), very typical leaf mosaic symptoms was noticed with mild to moderate distortion of leaf including mottling and crinkling of leaf.

In our present observation it has been found that intensity of CMD varied with plant age and severity was found high at maturity stage i.e. 6 months age of crops. It is predicted from this observation that intensity of symptoms at early crop growth stage expressed low intensity than mature stage.

This could be due to age of plant that may have direct relation with symptoms expression. Intensity of CMD expression varies with season and age of infection (Mishra et al., 2006). They also established that primary spread of the disease is through the planting material and secondary spread of the disease is through the insect vector, whitefly (Bemisia tabaci Genn.).

During studies on the incidence of CMD in some cassava growing areas, apparently high incidence of mosaic symptoms was noticed in the plants grown in North 24-parganas and Nadia districts, in contrast, a negligible number of plants showed CMD symptoms in the experimental field at HRS, BCKV. Cassava mosaic disease (CMD) has been cited on the most important cassava disease in major cassava grouping field of West Bengal.

There are several reports on the incidence of CMD in cassava growing states of India and causes $25-80 \%$ yield reduction (Edison et al., 2006). In India the cassava mosaic disease caused by also viruses namely Indian cassava mosaic virus (ICMV) and Sri Lankan cassava mosaic virus (SLCMV) (Malathi et al., 1983;
Dutt et al., 2005). Edison et al., (2006) reported cassava mosaic disease is caused by Indian cassava mosaic virus (ICMV).

The whitefly transmitted cassava plants were scored on the incidence of mosaic symptoms. In this study eight cassava varieties were assessed under force inoculation method. The green house studies revealed that variety Sree Jaya, Sree Prakash and H-118 to be easily infected by insect transmission and severe to mild infection was induced and the percentage of infected plants were 26.66, 33.33 and 40.0 respectively. Low rate of infection was noticed in the Sree Vijaya and H-119 (6.66\%) followed by $\mathrm{H}-165$ and $\mathrm{H} 5 / 78$ where the infection percentage was 8.88 and 16.66 respectively (Table 3 ). Among eight varieties high expression of symptoms was observed in the varieties like Sree Jaya, Sree Prakash and H-118 whereas a mild symptom was noticed in the rest of the varieties. In the PCR test excepting the varieties Sree Bijaya and CL590 gave positive reaction. In the PCR test excepting the varieties Sree Bijaya and CL590 gave positive reaction (Table 3 ).

With the gene specific primers pair of coat protein gene was amplified 511 bp fragment size and other primers pairs also amplified a fragment $750 \mathrm{bp}$ (Fig. 1a and b). The specific primers successfully amplified the most of the test plants of the cassava varieties was detected. The amplified products of the DNA were $511 \mathrm{bp}$ which confirm the presence of Cassava mosaic virus in the inoculated plants. The DNA samples from the Sree Bijaya and CL-590 failed to amplify though the plants showed mild symptoms. Expression of the band was very clear in the varieties like Sree Jaya, Sree Prakash and H-118 whereas H5/78, H-165 and H-119 also amplified 511 bp products with mild reaction. The DNA samples of all he inoculated plants of eight varieties of cassava were further analysed to resolve ambiguous results in the agarose gel. 
Table.1 The different isolate of SLCMV and ICMV with its genbank accession number used for comparative sequence analysis

\begin{tabular}{|c|c|c|c|}
\hline SI. No. & Name of the isolate & Country & Accession No. \\
\hline $\mathbf{1}$ & West Bengal & India & FN691429 \\
\hline $\mathbf{2}$ & Sri Lanka, TN2 & India & AJ890227 \\
\hline $\mathbf{3}$ & Sri Lanka, TN7 & India & AJ890229 \\
\hline $\mathbf{4}$ & Sri Lanka, Kerala 15 & India & AJ890224 \\
\hline $\mathbf{5}$ & Sri Lanka, Kerala 17 & India & AJ890225 \\
\hline $\mathbf{6}$ & Sri Lanka, TN 6 & India & AJ890228 \\
\hline $\mathbf{7}$ & Sri Lanka, Kerala 20 & India & AJ579307 \\
\hline $\mathbf{8}$ & Sri Lanka, Colombo & Sri Lanka & AJ314737 \\
\hline $\mathbf{9}$ & Maharashtra & India & AJ314739 \\
\hline $\mathbf{1 0}$ & Sri Lanka, Kerala C4 & India & AJ890226 \\
\hline $\mathbf{1 1}$ & Kerala (Kolli hills) & India & AY998122 \\
\hline $\mathbf{1 2}$ & Kerala-A & India & AY769966 \\
\hline
\end{tabular}

Table.2 Disease incidence and severity of Cassava Mosaic Disease farmers' fields and in the experimental field, Mondouri, BCKV

\begin{tabular}{|c|c|c|c|}
\hline \multirow{2}{*}{ Name of the place } & Disease incidence in percentage & Disease severity & $\begin{array}{c}\text { Age of the } \\
\text { crops in month }\end{array}$ \\
\cline { 2 - 4 } & Mean & Mean & 4 \\
\hline Farmers' field, North & 82.66 & 1.97 & 5 \\
\hline Farmers' field, & 81.33 & 2.22 & 6 \\
\hline Saguna, Nadia & 92.00 & 3.14 & 4 \\
\hline Experimental field, & 61.33 & 1.69 & 5 \\
\hline Mondouri, BCKV & 73.33 & 2.42 & 6 \\
\hline & 77.33 & 2.74 & 4 \\
\hline
\end{tabular}

Table.3 Expression of symptoms and PCR reaction of the artificially inoculated cassava plants of eight varieties

\begin{tabular}{|c|c|c|c|c|}
\hline SI. No. & $\begin{array}{c}\text { Varieties/ } \\
\text { Cultivars }\end{array}$ & $\begin{array}{c}\text { Number of plants } \\
\text { inoculated }(\mathbf{3} \text { sets) }\end{array}$ & $\begin{array}{c}\text { Percentage of plants } \\
\text { showing CMD symptoms }\end{array}$ & $\begin{array}{c}\text { Reaction to } \\
\text { PCR }(+/-)\end{array}$ \\
\hline $\mathbf{1}$ & H-5/78 & 12 & 16.66 & + \\
\hline $\mathbf{2}$ & Sree Jaya & 15 & 26.66 & +++ \\
\hline $\mathbf{3}$ & Sree Bijaya & 15 & 6.66 & - \\
\hline $\mathbf{4}$ & Sree Prakash & 15 & 33.33 & +++ \\
\hline $\mathbf{5}$ & H- 165 & 12 & 8.33 & + \\
\hline $\mathbf{6}$ & CL-590 & 10 & 8.33 & +++ \\
\hline $\mathbf{7}$ & H-118 & 15 & 40.0 & + \\
\hline $\mathbf{8}$ & H-119 & 12 & 6.66 & + \\
\hline
\end{tabular}


Fig.1 a and b Virus amplification by polymerase chain reaction

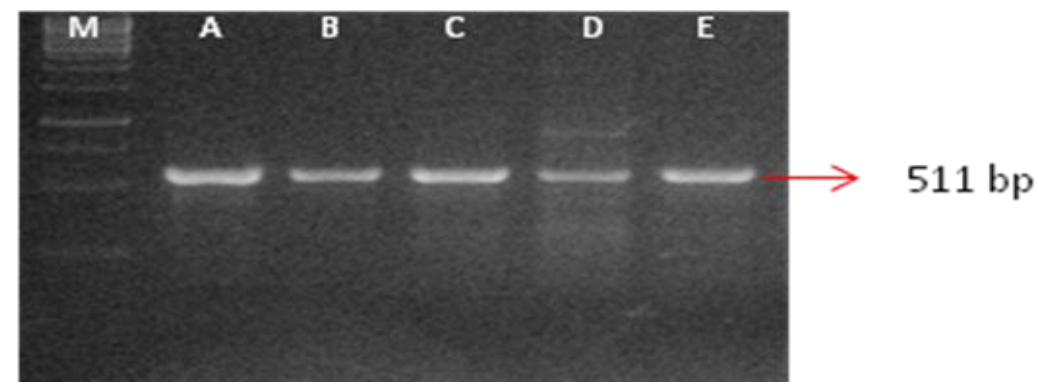

(a)

PCR amplification by gene specific primers for AV1 in the different cultivars: M- leader, A, B, C and D from H118 and E-from Sree Prakash with Same size 511 bp.

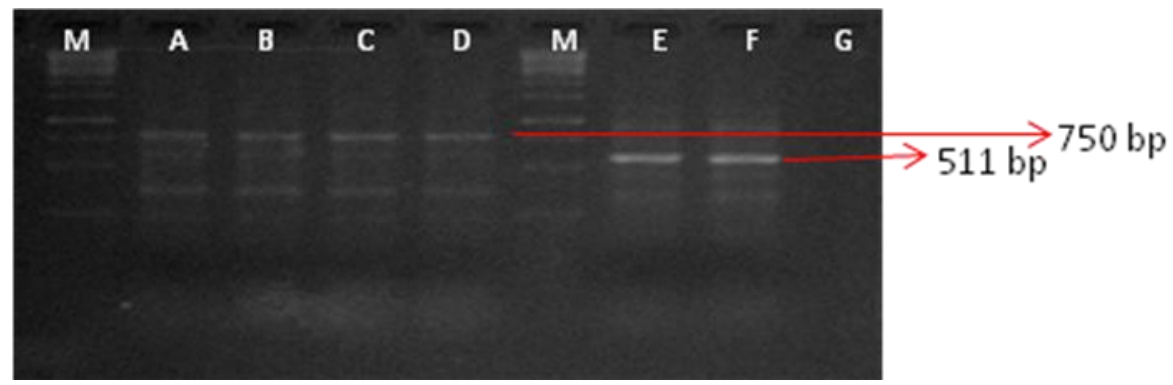

(b)

PCR amplification by degenerate primers for a part of DNA-A in the different cultivars: M- leader, A, B, C and D from $\mathrm{H} 118$ and $\mathrm{E}$ and $\mathrm{F}$ from $\mathrm{H} 118$ by the whitefly transmission, $\mathrm{G}$ is control.

Fig.2 Neighbour-joining tree constructed from an alignment of partial and complete nucleotide sequence of coat protein gene from cassava mosaic virus, using Clustal W2 programme, average distance shows using BLOSUM 62

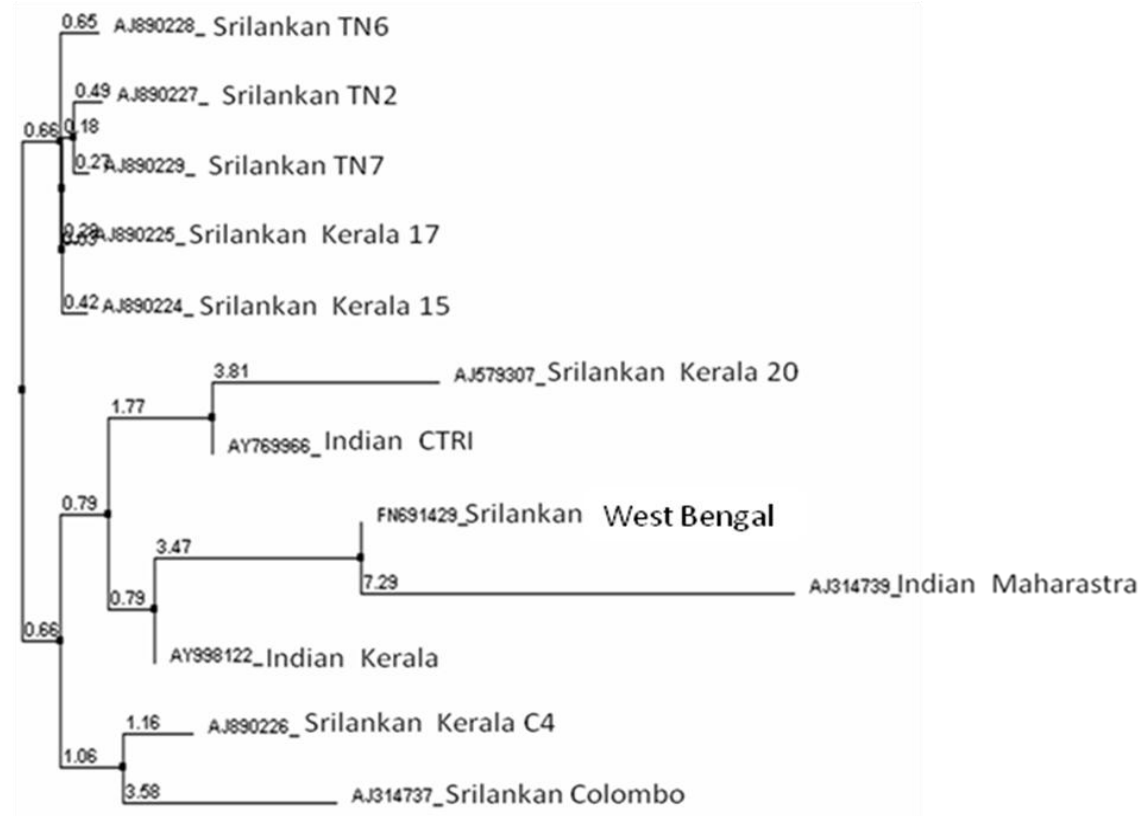


However, the PCR test confirmed that the virus infected the cassava plants in the field of West Bengal is the Cassava Mosaic Virus which was successfully transmitted by the insect vector in the inoculated plants which produced CMD symptoms.

The differences in the severity of infection symptoms with respect to the virus and cassava varieties clearly suggested that differences in the virulence of the virus isolate (West Bengal Isolate) of the CMD as well as differential levels of susceptibility of the cassava varieties against whitefly and virus isolate. The importance of molecular based screening techniques in differentiating between field resistance response and immunity to Cassava Mosaic Virus infection. (Briddon et al., 1993) described the PCRbased method for mosaic virus infection in cassava and they reported that few samples amplified poor during the studies. Our present results obtained during PCR screening of inoculated plants indicated that PCR based approach is able to consistently identify the virus infection in cassava. The nonappearance or poor amplification of band in the suspected plants would be due to very low titre of virus in the extracted plant samples or infection of other strains. Ogbe et al., (2003) assayed the concentration of African cassava mosaic virus (ACMV) in relation to symptoms severity in cassava genotypes and they suggested that genotypes displaying mild symptoms, but with high levels of virus accumulation, could be an important source of inoculums in the spread of ACMV by the whitefly vectors.

In our present studies it was found that the inoculated plants of Sree Bijaya, H-5/78 and H-119 with mild to moderate symptoms did not amplify in PCR but this would play vital role in transmission by whiteflies. However, the present finding strongly supports the previous reports.
Alabi et al., (2008) reported the use of multiplex PCR for detection mixed infection of variable strains of cassava mosaic virus. Patil et al., (2005) demonstrated first time that presence of both Indian cassava mosaic virus (ICMV) and Sri Lankan cassava mosaic virus (SLCMV) affected cassava plants from different field locations in India using Polymerase Chain Reaction (PCR). In our present investigation, it is predicted that the DNA samples of inoculated plants and field symptoms amplified the fragment of SLCMV. Further, the DNA fragment was sequenced and submitted to NCBI which confirmed the sample is infected with SLCMV. However the results on PCR detection confirmed that the artificially inoculated cassava plants and the plants used for the virus source are the same virus infecting cassava.

The analysed sequence of the Cassava Mosaic Virus from West Bengal isolate (FN691429) was blasted and found that the fragment of size 511 bp is closely related to coat protein (CP) gene from Sri Lankan cassava mosaic virus isolates. The alignment of nucleotide sequence was done using Clustal W2 software and found that Bengal isolate (FN691429) was closely related (99\%) with AV1 gene (Coat Protein) of other isolates of SLCMV like Tamil Nadu 7, Kerela 7, Kerala 15, Tamil Nadu 6 and Kerala 20 followed by Tamil Nadu 2 with $98 \%$ identity. West Bengal isolate also found similar homology (99\%) with the two Indian cassava mosaic virus coat protein identity, whereas $92 \%$ homology was found with Sri Lankan cassava mosaic virus from Colombo (Fig. 2). Our present investigation confirmed that the CMV occurring in West Bengal is the SLCMV and partial cds of AV1 gene showed high similarity with SLCMV from South Indian isolates. It is therefore predicted that occurrence of SLCMV isolate in West Bengal has high epidemiological significant and evolutionary important for further studies. 


\section{References}

Alabi, O.J., Kumar, P.L. and Naidu, R.A. 2008. Multiplex PCR for the detection of African cassava mosaic virus and East African cassava mosaic Cameroon virus in cassava. J. Virol. Methods, 154(1/2): 111-120.

Allen, C.A. 1994. The origin of Manihot esculenta Crantz (Euphorbiaceae). Genet. Resour. Crop Evol., 41: 133-150.

Briddon, R.W., Prescott, A.G., Lunness, P., Chamberlin, L.C.L. and Markham, P. 1993. Rapid production of full-length, infectious geminivirus clones by abutting primer PCR (AbP-PCR). J. Virol. Methods, 43: 7-20.

Dellaporta, S.L., Wood, J. and Hicks, J.B. 1983. A plant DNA minipreparation: version II. Plant Mol. Bio. Rep., 1: 1921.

Dutt, N., Briddon, R.W. and Dasgupta, I. 2005. Identification of a second begomovirus, Sri Lankan cassava mosaic virus, causing cassava mosaic disease in India. Arch. Virol., 150(10): 2101-2108.

Edison, S., Anantharaman, M. and Srinivasan, T. 2006. Production technologies of cassava. In: Status of cassava in India. An overall view, CTCRI, ICAR, Trivandram, Kerala, pp. 50-69.
Hahn, S.K., Terry, E.R. and Leuschner, K. 1980. Breeding cassava for resistance to cassava mosaic disease. Euphytica, 29: 673-683.

Malathi, V.G. and Sreenivasan, M.A. 1983. Association of Gemini particles with cassava mosaic disease in India. J. Root crops, 9: 69-73.

Misra, R.S., Nair, R.R. and Jeeva, M.L. 2006. Diseases of Tuber crops. Kisan world, 33(11): 23-24.

Ogbe, F.O., Thottappilly, G., Dixon, A.G.O., Atiri, G.I. and Mignouna, H.D. 2003. Variants of East African cassava mosaic virus and its distribution in double infections with African cassava mosaic virus in Nigeria. Plant Dis., 87(3): 229232.

Olsen, K.M. and Schaal, B.A. 2001. Microsatellite variation in cassava (Manihot esculenta, Euphorbiaceae) and its wild relatives: further evidence for a southern Amanzonian origin of domestication. Am. J. Bot., 88: 131-142.

Patil, B.L., Rajasubramaniam, S., Bagchi, C. and Dasgupta, I. 2005. Both Indian cassava mosaic virus and Sri Lankan cassava mosaic virus are found in India and exhibit high variability as assessed by PCR-RFLP. Arch. Virol., 150(2): 389-397.

\section{How to cite this article:}

Nayan Kishor Adhikary, Manoj Kumar and Jayanta Tarafdar. 2018. Occurrence of Sri Lankan Cassava Mosaic Virus (SLCMV) and its Characterization in West Bengal, India. Int.J.Curr.Microbiol.App.Sci. 7(01): 2887-2893. doi: https://doi.org/10.20546/ijcmas.2018.701.344 